\title{
EPISTEMOLOGIA DA ARTE: O FRUIDOR E O OBJETO DE ARTE
}

\section{EPISTEMOLOGY OF ART: THE FRUITION AND ART OBJECT}

Tiziana Cocchieri ${ }^{1}$ 


\section{Resumo}

Por meio deste artigo, trazemos uma perspectiva da relação sujeito/objeto, fruidor/objeto de arte ${ }^{1}$, refletida no prisma das implicações presentes no processo de construção de significado da leitura de imagem. As considerações apontadas são tecidas a partir do objeto de arte, traduzidas por meio da multiplicidade de leituras possíveis, que fornecem subsídios enfatizando a subjetividade como volição, porém, dissertando a partir de caminhos de significação objetiváveis. Para explicitar esta relação, o primeiro aspecto a ser exposto diz respeito ao caráter expressivo da necessidade da razão como parte do processo que faz emergir significado, considerando extremos conceituais e os conteúdos de verdade das múltiplas facetas do objeto de arte, fundindo-se ao conteúdo crítico deontológico. O segundo ponto, parte da tese sobre a qual a arte se delineia mediante espaço conceitual, formado a partir da subjetividade que se inicia no sujeito que configura o objeto. Neste contexto, os objetos de arte apontam para a subjetividade do artista e do fruidor na construção de sentido, por meio de um processo imbricado de criação, em que seu contraponto se apoia sobre a objetividade da realidade material do objeto reverberada através do repertório conceitual do sujeito. Trazemos também para este contexto a autonomia presente na construção de significação conceitual enquanto substrato de verdades possíveis, com intuito de delinear campos de significação.

Palavras-chave: Epistemologia. Objetividade. Subjetividade. Fruição. Objeto de arte.

\section{Abstract}

In this article, we present a perspective on the subject / object, spectator / object ofart relations, reflected through the prism of the implications present in the meaningmaking process of image reading. The mentioned considerations are woven from the art object, translatedthrough the multiplicity of possible readings. These readings emphasize subjectivity as volition, however, expounding from paths of objective significance. To explain this relationship, we firstexplain the expressive character of the need for reason as part of the process that brings outmeaning, considering the extreme conceptual and real content of the multiple facets of the artobject, merged with critical ethical content. The second part of the thesis holds that art is delineated by a conceptual space, formed from the subjectivity that begins in the subject that sets up the object. In this context, art objects point to the subjectivity of the artist and the spectator in the construction of meaning, through an elaborate creation process. The counterpart to this process is based on the objectivity of the real material object, which reverberates through the conceptual repertoire of the subject. We also bring to this context the autonomy present in the construction of conceptual significance as substrate possible truths, in order to delineate significant areas.

Keywords: Epistemology. Objectivity. Subjectivity. Fruition. Art object.

ISSN 2175-2346 
Procuramos partir da perspectiva das artes visuais para expor a relação entre fruidor e objeto de arte, buscando no repertório teórico da epistemologia filosófica a similitude que perpassa esta relação, com intuito que esta forneça corolário lógico-argumentativo para a compreensão da construção de significado na elaboração de leitura de imagem. A relação sujeito/objeto é recorrente ao longo de toda história da filosofia e tema central no que tange pesquisas sobre epistemologia, pois trata da relação entre o sujeito que observa e interpreta seu entorno e o objeto que é analisado e lido por este sujeito. Como este tema é bastante extenso e cheio de imbricações complexas, não pretendemos criar digressões em seu entorno. Logo, faremos um recorte para atender ao nosso propósito, que abranja o contexto da polarização clássica: sujeito (teor de subjetividade representacional)/objeto (mundo a ser interpretado) apresentado por um ponto de partida específico, a saber, a leitura feita pelo fruidor (sujeito) sobre o objeto de arte (objeto).

De modo distinto ao da dicotomia clássica sujeito/objeto, a natureza imagética da arte nos permite abordar essa relação por meio de uma tricotomia esquematizada por: fruidor, representação mental, objeto de arte; estes presentes em um processo relacional entrelaçado, indissociável e irredutível da/na fruição estética. O foco acaba por ser direcionado para responder às questões: O que há de objetivo na leitura subjetiva da fruição em arte? Retoricamente, se o processo de fruição de objetos artísticos não possui necessariamente estrutura subjacente cognoscível, como poderíamos classificá-los como educacionais? Como qualificar, estabelecendo critérios objetivos, os objetos de arte em meio a processos de seleção nas exposições de arte? E se assumimos a hipótese de serem estes processos necessariamente cognoscíveis, como se configuram?

Mediante estas questões, procuramos defender a tese de que há necessariamente nesses processos, além destes estarem permeados de carga emocional e expressiva, uma estrutura subjacente cognoscível passível de objetivação. Para desenvolvermos a argumentação sobre os problemas colocados acima, partiremos das seguintes hipóteses:

a) A subjetividade presente na fruição é indissociável da objetividade intrínseca ao objeto de arte.

b) O objeto de arte é per si de natureza híbrida: ontológica (o ser do objeto) e deontológica (possibilidade do que deve ser).

c) A formação e expansão de visão de mundo e espaço conceitual do fruidor faz parte fundamental do processo de criação e construção de significado do objeto de arte, na medida em que abarca as relações: sujeito/objeto, subjetividade/objetividade, ontologia/deontologia, mente/mundo, por meio da sincronicidade entre objeto de arte e o entorno em que está inserido contextualmente.

A arte traz consigo um campo em que a subjetividade se manifesta como espaço de criação de significado, não só por parte do artista criador, como também por parte do fruidor, enfatizado neste contexto. Com isso, como dito anteriormente, intentamos descrever como está imbricada, de modo indissociável, a relação sujeito/ objeto percebida em analogia à relação fruidor/objeto de arte, porém introduzindo um terceiro elemento ao da configuração filosófica tradicional, que é a representação mental (SILVEIRA, 2007, pp. 38-59). Este elemento medeia a relação entre a coisa 
e a impressão que ela provoca ao se revelar através do objeto em contato com o repertório contido no sujeito.

Há teor de subjetividade e de objetividade associados e mediados em complexa relação, nem sempre mensuráveis ou passíveis de identificação. No entanto, mesmo sendo uma relação dinâmica, há elementos que são apreensíveis, que tomam forma de um padrão. Por analisarmos a imagem, a estrutura ordenada de forma causal contida nas sentenças (próprias do aparato argumentativo que compõe as teorias), não se aplica às figuras percebidas em relação, pois, estas imagens se configuram em experiência simultânea que se configura na forma de representação mental. Trata-se de uma relação que poderia ser representada por meio de estrutura risomática dinâmica, em que as concatenações se constroem como sinapses, conectando-se em múltiplas combinações simultâneas.

\section{O ser do objeto de arte e sua natureza deontológica}

Ao delinear o ponto de partida para a construção do processo de significação da materialidade fenomênica do objeto de arte, analisamos estruturas subjacentes que estão presentes no contexto da leitura do mesmo objeto, considerando a adoção da hipótese da cognoscibilidade adjacente presentes nos processos de fruição. Neste sentido, descrever esta estrutura seria tão relevante, quanto discernir as marcas sulcadas pela cultura e os sinais das múltiplas vivências individuais e coletivas materializadas nesses mesmos objetos. Buscamos focar na análise dos elementos que poderiam constituir-se como padrão, sem preterir a presença da pura qualidade, ou seja, do que é irredutível a um padrão mensurável.

Em outro dizer, enfatizamos a subjetividade presente no artista, como no fruidor, plasmada na própria materialidade objetual da produção estética, como também na singularidade da expressão sígnica do objeto de arte. Buscando, através de um viés representacional, compreender a estrutura de delimitação de espaços conceituais (BODEN, 2001) e configuração de visões de mundo.

As novas ideias se mostram possíveis por meio da compreensão dos elementos constitutivos: eventos, sensações, situações inseridas em um espaço conceitual, ou seja, relacionadas a princípios organizadores que unificam e dão estrutura a um dado domínio de pensamento. Além de se mapear o espaço conceitual e compreender seu funcionamento, há também a possibilidade de expansão ou transformação desse espaço, na medida em que novas relações são formadas, a partir da tríade básica relacional citada anteriormente.

Neste sentido, a arte aponta para um caminho, ao abordar a esfera da objetividade presente na realidade fenomênica existente no objeto artístico, que desemboca na percepção compartilhada da leitura de múltiplas subjetividades; incluindo os registros emocionais de vivências e categorias mnemônicas, que, em última análise, no decorrer do processo de significação, nos remete à busca da compreensão de identidades e classificação das diferenças. Assumimos a tese de que esta estrutura, que está presente na construção de teorias, também está presente na construção representacional do objeto artístico, em que seu significado é construído a partir do 
delineamento de espaços conceituais, porém, ambas se apresentam de forma idiossincrática e de acordo respectivamente com a natureza narrativa (esquematizada) e imagética (experienciada).

Ainda em contexto idiossincrático, ao recorrermos a um método que nos leve à compreensão sígnica do objeto de arte, estamos analisando a constituição de um ente que está limitado em sua materialidade; mas, que possui certa autonomia no sentido de ser lido como sistema aberto, com diversidade de significações e espaço conceitual dinâmico e flexível, que pode expandir-se ad continuum. A limitação da materialidade em dado tempo é o que restringe as possibilidades de construção e de significado, na medida em que se configura como negação. Seria possível com isso atribuir significados do que o objeto possa ser, porém, sem contradizer os aspectos de sua materialidade, tampouco seria possível reconhecer suas formas sem que haja um correspondente conceitual para dar-lhe estofo.

Expondo de outro modo, podemos construir significações sobre o objeto de arte de forma bastante livre (por meio de livres associações) ${ }^{1}$, porém, o repertório conceitual que temos como substrato de percepção imagética é o que nos orienta quanto ao seu reconhecimento e inteligibilidade. Neste aspecto a identidade do objeto, para que o mesmo seja lido de modo cognoscível, deve ser preservada. Há outros elementos em intersecção, colocados em relação com os campos da ética e estética, aparecendo no teor deontológico (possibilidade de dever ser), pois há um compromisso com a verdade entendida como factualidade, ou seja, como fato fenomênico, como acontecimento. $O$ conceito de ética exposto aqui se refere ao ponto de vista de Dewey, que entende que ética se relaciona à noção de valor. No dicionário de Filosofia de Abbagnano aparece esta descrição conceitual à qual estamos nos concentrando de forma bastante pontuada:

Dewey tem em comum com boa parte da filosofia do valor a crença de que os valores são não só objetivos, mas também simples e, portanto, indefiníveis, mas não a crença de que eles são absolutos ou necessários. Para Dewey, os valores são qualidades imediatas sobre as quais, portanto, nada a que dizer; só em virtude de um procedimento crítico e reflexivo é que podem ser preferidos ou preferidos (Theory of Valuation, 1939, p. 13). Mas, eles são fugazes e precários, negativos e positivos, além de infinitamente diferentes em suas qualidades. Daí a importância da filosofia, que, como 'crítica das críticas', em primeiro lugar tem o objetivo de interpretar acontecimentos para deles fazer instrumentos e meios da realização dos valores, e em segundo lugar, o de renovar o significado dos valores (Experience and Nature, pp. 394 ss.). Essa tarefa da filosofia é condicionada pela renúncia à crença na realidade necessária e no valor absoluto. $(2007$, pp. 448, 449)

\footnotetext{
1 Este conceito aparece na obra de C. S. Peirce denominado Musement, significando a livre associação de ideias que antecedem os processos de raciocínio lógico. Vide M. H. Fisch, "Introductory Note", The Play of Musement, T. A. Ed. Sebeok, Indiana University Press, Bloomington, 1981, p. 17. Também na tradução original para o português em: PEIRCE, C. S. Um argumento negligenciado para a realidade de Deus. Trad. Cassiano Terra. In: Revista Cognitio, v.4, n. 1, pp. 98-133, jan-jun. 2003. Ainda no original em inglês: CP 6.640-641: "In any mere Play they can be used by way of exercise alone; while logical analysis can be put to its full efficiency in Musement. So, continuing the counsels that had been asked of me, I should say, 'Enter your skiff of Musement, push off into the lake of thought, and leave the breath of heaven to swell your sail. With your eyes open, awake to what is about or within you, and open conversation with yourself; for such is all meditation.' It is, however, not a conversation in words alone, but is illustrated, like a lecture, with diagrams and with experiments. [...] I have sometimes been half-inclined to call it reverie with some qualification; but for a frame of mind so antipodal to vacancy and dreaminess such a designation would be too excruciating a misfit. In fact, it is Pure Play. Now, Play, we all know, is a lively exercise of one's powers. Pure Play has no rules, except this very law of liberty. It bloweth where it listeth. It has no purpose, unless recreation. The particular occupation I mean - a petite bouchée with the Universes - may take either the form of aesthetic contemplation, or that of distant castle-building (whether in Spain or within one's own moral training), or that of considering some wonder in one of the Universes, or some connection between two of the three, with speculation concerning its cause. It is this last kind - I will call it "Musement" on the whole - that I particularly recommend, because it will in time flower into the N.A." Disponivel em: <http://www.commens.org/dictionary/term/musement> . Acesso em: 06.05.2016. [Grifo nosso].
} 
Em alguns pontos, os modelos filosóficos clássicos podem fornecer descrições de estruturas sistematizadas que corroborem para a compreensão de como a relação, aparentemente polarizada, se configura paralelamente de modo dicotômico. Pois, o que nos é vedado afirmar é o que o objeto não é, ou seja, dizer que objeto de arte possui características referentes à sua materialidade que não corresponde factualmente a ela mesma não seria ético, não teria valor de verdade a respeito das relações construídas sobre a correspondência com a realidade fenomênica do objeto. Porém, ele, o objeto de arte, não se limita somente a esta relação de materialidade, seu teor representacional amplia suas possibilidades sígnicas, ainda que restringido à sua materialidade. A dialética aparece aqui como método de identificação de semelhanças e diferenças, porém a estrutura relacional triádica entre fruidor, representação mental e objeto de arte permanece válida.

Para descrever esse processo de modo didático, tomemos como exemplo, o trabalho de Ed Ruscha, Noise [1963]. Suspendendo a força do tempo, do contexto histórico, e pinçando a leitura do processo sígnico; este é um construto que serve de visor para que possamos entender um dos modos com que se processa a leitura de objetos artísticos, enfatizando seu teor cognoscível. Este objeto de arte tomado por expressão faz parte do repertório de arte conceitual, o que favorece nosso campo de leitura, tendo em vista que faz parte da natureza discursivo-filosófica a descrição conceitual, para compreender a configuração transposta a partir do espaço conceitual para o plano da imagem (e vice-versa), tanto em sua expansão como limitação. Outro fator que favorece nossa análise é o fato deste trabalho não ser recorrentemente divulgado, logo, não há muita literatura previamente sistematizada sobre ele, o que nos permite olhar, observar, antes de buscar referências e sistematizações convencionalmente estabelecidas.

A partir da evocação de diversos conceitos, torna-se possível delinear a presença subjetiva do agente (quer autor ou fruidor) que escolhe de modo aparentemente arbitrário sua via de construção, levando em conta as múltiplas e multifacetadas referências, que por sua vez emergem de um dado espaço conceitual. Neste sentido, a delimitação do espaço conceitual poderia configurar-se em um padrão, ainda que complexo e instável, porém, teoricamente objetivável. Façamos um exercício de análise, de caminhos possíveis e cognoscíveis de fruição. Primeiro sobre o trabalho de Ruscha ${ }^{2}$.

2 Imagem disponível em:< http://artobserved.com/2010/09/ao-on-site-stockholm-ed-ruscha-fifty-years-of-painting-at-moderna-museet-through-september-5th-2010/>. Acesso em 06.06.2016. 


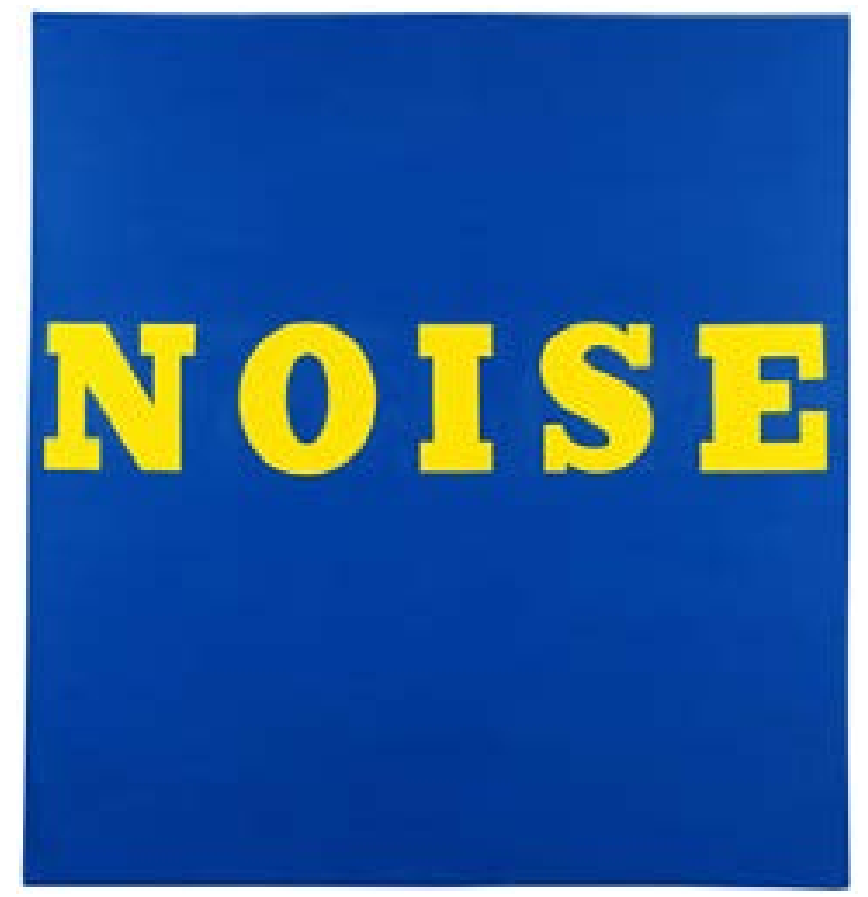

Em primeira análise, o desenho da palavra "ruído" (tradução do inglês noise para o português), grosso modo, está imbricado ao significado relacionado ao som, que não emite significação objetiva. Esse barulho não comunica algo que possua sentido semântico, pois, segundo Shannon ${ }^{3}$, o conceito de ruído é justamente uma restrição de linguagem, uma distorção originada da compreensão imperfeita emitida por parte do gerador informacional. Por que ruído não poderia ser entendido como um som simplesmente, ao invés de barulho? Justamente por haver uma expectativa de recepção informacional. Porém em seu teor mnemônico, a palavra ruído, leia-se representação mental, pode ser construída ou concatenada a camadas de significação e jogos relacionais inusitados, em que se questiona, por que não poderia ser um som, no que tange, em última análise, o conceito do que é música, desembocando na reflexão: por que ruído não poderia ser música? Pois os sons, ainda que ruidosos, podem remeter a significados concernentes a diversas vivências, trazendo em seu bojo a capacidade de ordenar e classificar e reclassificar, em sistema aberto e ampliando o espaço conceitual. Tanto o ordenar como o classificar, ambos fazem parte de processos cognoscíveis, ou seja, passíveis de inteligibilidade. Neste experimento mental proposto passamos hipoteticamente por um exercício de transliteração do discurso para a memória da experiência sensorial.

Por outro lado, deslocando a perspectiva do agente para o discurso, lembramos que este é um ruído sem som, pois só nos aparece o desenho da letra, sem que possamos ouvir algo. Neste sentido, o processo mental sinestésico se desenvolve por meio conceitual, pois ao pensar em "ruído" o entendimento de som é evocado. Logo, há cognição, e não somente emoção e imaginação, este elemento cognoscitivo, parte do espaço conceitual, se constitui como parte do processo de fruição.

Complexificando um pouco mais nosso processo de fruição, as camadas de construção de significado e ampliação do espaço conceitual do que foi exposto an-

SHANNON, Claude E. \& WEAVER, Warren. Teoria matemática da comunicação. Tradução de Orlando Agueda. São Paulo / Rio de Janeiro: Difel, 
teriormente seria delimitado pelo estofo do agente que domina um determinado código, neste caso, o da língua inglesa. Para seguir nesse processo sugerido, sem o domínio da língua, o caminho de significação se constrói de outra maneira, sem estabelecer esta relação com o significado convencionado da língua. Outro ponto de partida para uma ordenação da informação, da palavra noise, se delinearia com vistas no desenho das letras em concatenação fonética, em um processo contínuo de desdobramentos de significações a partir da forma relacionada ao som, ou mesmo às cores referentes ás frequências sonoras. Logo, a cor também é outro elemento a ser lido. Neste caso, na condição de pura qualidade que poderia derivar em adjetivações, associações de livres jogos relacionais, emocionais ou códigos convencionados. Algo também a ser considerado diz respeito à combinação de todos os elementos em sua totalidade, na plasticidade do conjunto, que não se reduz a suas partes. O porquê de estar onde e como estão, conquistam relevância conjuntamente, em seu todo.

Esta abordagem de fruição pode ser aplicada em diversas análises que envolvam as categorias de objetividade e subjetividade postas em relação. Cada qual ligada a contexto específico, mediante um repertório conceitual peculiar e configuração de espaços conceituais dimensionalmente múltiplos; que poderiam variar em graus de objetividade e subjetividade, de acordo com cada contexto de construção de significado que seja dominante no próprio objeto de arte, considerando um sistema aberto de relações sígnicas.

No entanto, quer se tome um caminho ou outro (leitura predominantemente subjetiva ou objetiva) ao ordenar o processo de significação, na leitura do objeto de arte não há erro; pois, não há o compromisso de correspondência simétrica entre representação perceptual e a realidade; na arte não se pretende descrever o que o mundo é, tal qual o cientista o faz, porém, busca o entendimento, o sentido de um mundo construído a partir de um singular - o artista, e quanto ao fruidor lhe é apresentado o desafio de construir significação a partir do próprio objeto de arte. Quer se tome uma perspectiva ou outra para a ordenação dos elementos transliterados para sentenças, qualquer um deles é válido e potencializa a construção/compreensão deste mesmo objeto frente à somatória das múltiplas leituras subjetivadas, em um crescente. O que invalidaria as concatenações da relação triádica de construção de significado mediante a leitura do objeto de arte, como dito anteriormente, seria atribuir ao objeto qualidades contraditórias à sua própria realidade material. Em outro dizer, quer em uma ou em outra abordagem, o valor de verdade factual se mantém eticamente válido, pois, tanto um como outro ponto de partida contêm teor de realidade abstrata e concreta, válidas enquanto construção e conexão de relações; considerando que o significado se constrói a partir da realidade fenomênica do próprio objeto, de como ele aparece no mundo e para um sujeito que reflete sobre sua ontologia.

Ao deslocarmos o olhar para um mais amplo labor de construção de significado, a objetividade também está presente, pois os conceitos não são privados, pelo contrário, existem para serem compartilhados. Dialeticamente, são parte intrínseca do espaço conceitual do agente, hora de forma mais aparente, hora em emaranhados sígnicos, se configurando por meio dos processos de representação mental em contextos diferenciados e dinâmicas distintas. 
A hipótese levanta aqui é de que o aparato cognitivo que possibilita a criação de teorias, em sua formação, em princípio é o mesmo da produção do objeto de arte. As semelhanças começam na geração de hipóteses, tanto as plausíveis pertinentes ao comprometimento da formulação de teorias, quanto na geração de significações atribuídas ao objeto de arte pelo fruidor, como na seleção da forma do objeto material para o artista. Peirce argumenta que:

O trabalho do poeta ou novelista não é tão profundamente diferente do homem da ciência. $\mathrm{O}$ artista introduz uma ficção, porém não uma ficção arbitrária; essa ficção demonstra certas afinidades às quais a mente atribui uma certa aprovação [...]. As realidades compelem-nos a colocar algumas coisas num relacionamento estrito, e outras em um relacionamento nem tão estrito, de modo altamente complicado e inteligível no (para?) o próprio sentido; mas é a habilidade da mente que apanha todas essas sugestões de sentido, acrescenta muita coisa a elas, torna-as precisas e as exibe numa forma inteligível nas intuições do espaço e do tempo. [1995, p. 17]

A diferença de um contexto para o outro irá ocorrer em momento ulterior. Em princípio, o que se pode considerar é a finalidade com que se pretende gerar hipóteses. No caso das formulações de teorias a verdade é gerada pela correspondência das hipóteses com a realidade testável, e no caso da arte, as verdades são geradas tendo em vista a coerência com seu objeto. De qualquer modo, em sua estrutura, ambos são caracterizados como processos permeados de razoabilidade.

Sobre estas relações, Santaella argumenta que:

A essência de um sistema processador de informação, um sistema físico de símbolos, está no fato de que ele codifica informação sobre o mundo, opera sobre essa informação de algum modo que pode ser caracterizado como significativo e está estruturado como um conjunto de partes interatuantes, funcionalmente organizadas. [2005, p. 60].

E, ainda em outro trecho, tece considerações sobre o conceito de verdade entendido pelo pragmatista W. James, a saber:

James se recusa sempre a nomear diretamente a "verdade" ou a "essência" que só existe para ele sob a forma de múltiplas aparências. Este preconceito,nos diz Todorov, afeta profundamente a organização de suas obras, chamando sua atenção para as técnicas do "ponto de vista" ou aquilo que James, ele mesmo, chama de "aquela obliquidade magnífica e magistral" (that magnificente and masterly indirectness). [SANTAELLA, 2005, p. 336].

Independente do delineamento do processo de significação que é atribuído aos conceitos de mente e de verdade, as representações perpassam pelos polos: singular e plural, particular e universal, subjetivo e objetivo; relações estas que estão presentes em diversos contextos, inclusive em construtos teoréticos coerentes e bem delimitados, pertinentes a contextos diversos do saber, inclusive nos mais rigorosos campos de ordenação de sistemas.

E não seria esta a seriedade e hegemonia das verdades produzidas em sua gênese pelo saber científico? Argumentamos que há uma ordem implicada e indissociável, que se delineia a relação sujeito/objeto. Ao tomarmos a tríade: fruidor/objeto de 
arte/ representação mental, procuramos dar visibilidade à geração de verdades que são produzidas em diversos contextos de formulação de hipóteses.

\title{
Possibilidade do que deve ser: a natureza híbrida do objeto de arte
}

Em sentido amplo, o próprio pensamento possui um caráter objetivo e constituído de materialidade. Para dar estofo a esta argumentação recorremos à tese do físico David Bohm, que reforça a argumentação de Peirce quanto às imbricações analogicamente articuladas entre mente e mundo (sujeito e objeto), pinçando um trecho de sua teoria sobre a Totalidade e Ordem Implicada (2008, p. 66):

\begin{abstract}
Assumindo que o pensamento é um processo material que pode ser relevante em algum contexto mais generalizado quando se move em paralelo com a percepção inteligente, somos agora levados a questionar a relação entre o pensamento e a realidade. Logo, é comum acreditar que o conteúdo do pensamento é algum tipo de correspondência reflexiva com as "coisas reais", talvez como sendo um tipo de cópia, ou imagem, ou imitação das coisas, ou talvez [junto com as linhas similares àquelas sugeridas por Platão] uma apreensão das formas mais internas e essenciais das coisas.
\end{abstract}

A própria materialidade do objeto de arte sugeriria uma leitura plural, que poderia variar em graus, por meio da dimensão do espaço conceitual. Neste sentido, tomamos por expressão o trabalho de Jane Sterbak, Quero que Você Sinta o que Eu Sinto ... (O Vestido), [1984-1985]

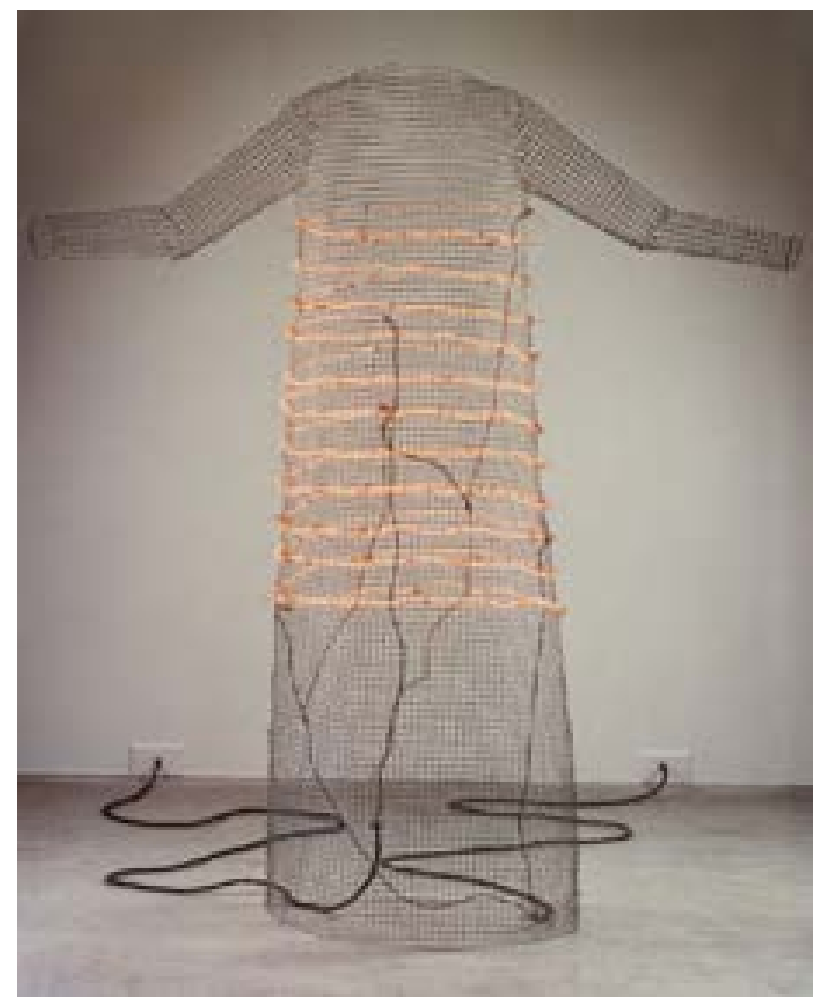


Este objeto de arte se caracteriza de modo distinto ao de Ruscha, pois se lhe acrescenta a tridimensionalidade, alterando assim a percepção e afetando o repertório da malha conceitual. Nesta obra, o título é considerado como nome do objeto, que ao nomeá-lo lhe dá parte de sua significação e sentido de existência. "Quero que você sinta o que eu sinto" evoca um desejo, uma presença subjetivada do agente que está a desejar. No entanto, este sujeito não está presente na cena, no objeto, é uma presença ausente.

$O$ vestido sem sujeito permite que qualquer um o vista. Sem cabeça, sem corpo e sem pé, somente roupa suspensa e armada; o sistema fica aberto à identidade que o queira vestir, sugerindo que ao vesti-lo se sinta o que eu sinto. Quem é este eu? Poderia ser um coletivo? Logo, a inversão da subjetividade do sujeito ${ }^{5}$ que veste é substituída pela objetividade (materialidade) do vestido que se torna o sujeito da cena. Este mover pode ser descrito como um sistema relacional de aparentes oposições, que poderia complexificar-se de acordo com o espaço conceitual que o possa delinear.

Outro elemento a ser considerado, diz respeito à transparência, na trama vazada do vestido e na translucidez, que faz passar a luz que o contorna, plasmado à substância concreta da veste, encharcada de pontos nodais de significação. Por exemplo, poderíamos partir da própria natureza da luz descrita por meio da polaridade energia/matéria. Na descrição do fenômeno luz, há uma natureza recorrente, abarcando em si o duplo estado: onda e partícula. Tecendo uma trama de significações para o objeto de arte produzido por Sterbak. Poderíamos evocar a metáfora da natureza da luz, relacionando-a com a dicotomia mente/corpo, em que colocamos em correspondência as leis que se aplicam ao mundo (objetividade) em relação ao agente cognoscitivo (subjetividade).

Buscamos na argumentação do filósofo/físico Goswami o estofo conceitual que dê base para nossa argumentação:

Todos os objetos quânticos evoluem como possibilidades em potentia transcendente até serem levados à imanência - o estado de coisa - pelo colapso via observação consciente. [...]. Na mecânica quântica, podemos correlacionar objetos de modo que permaneçam interconectados mesmo enquanto percorrem, em potentia, grandes distâncias. [...]. Obviamente, a correlação é não local, existente em um domínio de interconexão que transcende o domínio espaço-tempo imanente da realidade. $(2008$, p. 99$)$.

Neste sentido, "o vestido", e a sua leitura, poderia apresentar-se como pura possibilidade, no entanto, aparecendo com a materialidade vazada do arame e dúbia nas lâmpadas que remetem à natureza da luz. Esta abordagem está concatenada com um dado reportório conceitual, que se constrói a partir de referências apreendidas e/ou vivenciadas, desembocando em novas relações de natureza aberta e contínua. Obviamente, outras leituras são possíveis de acordo com o repertório de cada qual, porém sem que essa leitura esteja desconectada da materialidade do objeto estético. Se não houver relação com o objeto, a relação estabelecida não seria mais sujeito/ objeto como pretendemos apontar aqui. 
Expondo de outro modo esse sistema de relações, o mundo é uma esfera empírica onde se processa toda experiência humana, com a qual a arte justificaria sua permanência enquanto presença de necessidade em uma situação de carência de subjetividade. Em um mundo repleto de necessidades, e, nos voltando para a polarização necessidade/liberdade, a arte preenche o espaço de uma carência específica, carência de singularidade, de criatividade espontânea; que gera contradição e conflito, por considerar a necessidade, que está associada ao inexorável, e o desejo que pode ser construído em um querer deontológico.

Dito de outra forma, de modo geral a arte não se compromete em descrever a realidade como ela se apresenta ${ }^{6}$, mas, busca apontar leituras de realidade, de mundos possíveis ou não acessíveis. Como também poderia apresentar fantasias e conceitos não sistematizados, sem preterir a coerência com a materialidade do objeto, que é a condição de apresentação do que se pretende "dizer", por meio de uma cadeia de relações. Não creio que se produza arte se não para ser lida ou para ser expressa em uma forma diferente da habitual.

Uma das questões apresentadas, gravita em torno de como estão articulados estes polos, e de que modo suas verdades podem ser compreendidas, trazendo à tona o significado para a esfera da consciência. O significado é atribuído mediante um sistema que possa trazer coerência, tornando-se consciente na percepção da articulação dos elementos envolvidos nessa relação imagético-objetual, em que os significados criados estão relacionados ao objeto, tornam-se verdades em crescimento de combinações contínuas.

O que se manifesta para fora do sujeito que produz o objeto-de-arte está encarnado no aquém e além de seu objeto, sem que este se limite (ou a fruição esteja condicionada) a seu criador. Porém, o conteúdo subjetivo do artista influencia suas escolhas ao longo do processo de criação, por meio de um viés comum, que é a estrutura do aparato cognitivo. Logo, a fruição acontece, sem necessariamente considerar a intencionalidade daquele que a produziu. Pois, não há como ter acesso a este conteúdo intencional, salvo se este for manifesto. Há outra contingência, o agente nem sempre está consciente do que produziu, porém a presença da subjetividade amplia o repertório de relações em seu potencial criativo. Por não haver pretensões necessárias de manifestar sua intencionalidade, é dado espaço para que o fruidor participe e também imprima sua subjetividade na construção de significado, somando-se assim às múltiplas subjetividades, do que produz e dos que fruem.

Enfatizando a argumentação anterior, o objeto não é produzido ou mesmo lido mediante pura subjetivação, mas encontra-se em relação com a realidade e com a alteridade do mundo. Colocamos as perguntas retóricas: um objeto de arte pode ser pensado sem que haja manifestação de sua materialidade? E quem produz arte, se não um sujeito? Em termos gerais, este seria outro aspecto do teor de objetividade, como condição necessária, porém, não suficiente para pensarmos um objeto-de-arte.

Em síntese, o espaço conceitual se delineia em meio a essa tessitura de referências, pois é o conceito que medeia a relação de significação, necessária para que seja atribuído um sentido ao objeto, para torná-lo sensivel à atitude consciente. Convém

6 A física se compromete a fazê-lo, ou seja, a descrever a realidade de modo objetivo, por meio do discurso racional. 
enfatizar que percebemos por meio de conceitos ${ }^{7}$. Através do viés representacional, é proposto um recorte com fins de apontar para as verdades da arte, como elas podem ser cognoscíveis, como também tornam explícito o enfoque da relação sujeito/ objeto, sem polarizá-la. Considerando também que há a mediação da representação mental, que não é um meio, porém se constitui como um dos elementos desta relação.

\section{Formação da visão de mundo e o processo de construção de sig- nificado do objeto de arte}

Em esfera social, compreender a natureza do objeto de arte é uma atividade que corrobora para o desenvolvimento de uma consciência crítica da subjetividade, enquanto instância de resistência contra a totalização objetivada das esferas do que se entende por racionalidade humana. Assim, como não se deve atribuir ao objeto estético a função clínica de descrever a realidade, também não se deve escapar ao caráter de mediação do conceito; este é o ponto nodal que nos importa tocar aqui, a saber, como as verdades da arte tangem o caráter expressivo da necessidade da razão objetivada no teor conceitual. A relação do enigmático nas artes, enquanto linguagem cifrada e elementos que constituem este ser da arte potencializa o afastamento do que é produzido e no que se pode esperar ter sentido, ou entender, a partir da tríade: objeto-de-arte, representação, fruidor; mediante conteúdo de verdades não previamente estabelecidas ou convalidadas.

Neste sentido, o próprio agente está em processo, ao atentar para a percepção de outro sobre o que externalizou a partir de si. Pois, quanto ao corpo, podemos perceber quais os limites de nossa forma, de como ela se configura, nos vemos em espelhos. Mesmo que a percepção de si tenha forte teor subjetivo, que envolve complexas relações de autoimagem podemos ver nossos corpos através de espelhos, e somos reconhecidos em nossa identidade do corpo. No entanto, como perceber o que o corpo não mostra? Como termos o retorno sobre a configuração de nossa personalidade, por exemplo, se não por meio do outro? Não há espelho que nos mostre a alma. E mesmo que adotemos a imagem que se constrói, por meio do outro e de nosso entrono, de nós mesmos, ela própria não é a verdade. Novamente enfatizando que tomamos verdade como correspondência à realidade, mas, por sermos seres dinâmicos, em constante movimento e transformação, estamos por nos fazermos ser, mediante um norte deontológico, que nos guia por intermédio de um dever ser.

Somando-se múltiplas verdades, ou seja, diversas perspectivas fenomênicas sobre uma mesma subjetividade, esta nos é, por si, apresentada como elemento do devir, do vir a ser da mesma subjetividade. O que significa dizer que corresponde com as variadas leituras que os que estão fora do "eu" elaboram sobre o mesmo agente. O que enfatizamos com isso é que a subjetividade é também construída por meio de um coletivo, não se perfaz sozinha. A tese solipsista cartesiana, no contexto contemporâneo de percepção de realidade, não se sustenta. Mediante ferramentas disponíveis que nos possibilitam ver o microcosmo (microscópios, nanotecnologia e afins) e

HANSON, R. N. Patterns of Discovery. Cambridge: Cambridge University Press, 1972. 
as que nos permitem observar distâncias antes incomensuráveis, nos permite ampliar a percepção de como o mundo se configura. Neste sentido, tudo está conectado e tudo se perfaz, de forma direta, emergente ou superveniente; o que parece haver são desdobramentos e não quebras individualizadas ${ }^{8}$. Porém, a visão que se tangencia sobre o mundo é de que todos seus elementos estão em relação, que as antigas demarcações e topologias não estão contidas na totalidade do cosmos. As linhas que delimitam um conhecimento de outro, uma área de atuação de outra, servem como limite para diferenciarmos o um e o múltiplo, para separar didaticamente uma coisa de outras coisas. $O$ que não significa dizer que as relações que permeiam as coisas no mundo, mesmo que muitas delas não sejam percebidas de pronto, não estejam envoltas numa gama múltipla e mais abrangente e complexa de relações, como as camadas de uma cebola.

De modo análogo, no aspecto de contradição/complementaridade, o objeto de arte se encerra em sua apresentação. No que está posto do que seja o objeto em si, como um ente em sua condição de alteridade, que carece de significação. Porém, permanece com dinâmica intrínseca ao ser pensado de diferentes modos, a partir de múltiplas verdades idiossincráticas, com possibilidade de pensar-se a si no outro e no próprio processo de fruição, no embate com o objeto estético.

Seria o caso de trazermos novamente para o contexto a obra Noise, em outra possibilidade de leitura. Traduzindo, o que está posto na palavra "ruído", escrita sobre suporte, com seu fundo neutro, destacado em amarelo, se faz pronunciar um ruído agudo, que se destaca na relação figura/fundo, tornando evidente o que se pretende destacar, ou seja, a própria palavra. Não foi dito, não foi emitido som, o que há é silêncio. Surge como que por acidente, o que se interpõe ao que se pretende escutar, ou mesmo entender. Neste sentido, o quanto de ruído nós somos? Será que sempre que expressamos esta forma, ou quando a palavra aparece está acompanhada de sentido? O sentido se constitui e se configura como uma vestimenta que perfaz o devir. Vestimos camadas de significação em esferas diversificadas do mundo vivido.

Do mesmo modo acontece com o Vestido de Sterbak, ele apresenta sua materialidade, ainda que o corpo não esteja presente, seus índices acusam sua presença, há um formato de corpo que cabe ali, e que está ligado a sua representação, pois ao confeccionarmos vestidos o fazemos para pessoas, que possuem dimensões, medidas e se situam no mundo. Esta relação indexical, em que não aparece o corpo, aparece o vestígio do corpo, seu rastro, poderia nos remeter a este plano do que não é visto, porém está relacionado. Talvez esse corpo não possa ainda ser percebido, sem sabermos exatamente por que, sem sabermos a causa, mas que se mostra desta maneira, nos deixando impotentes e perplexos frente à factualidade do objeto que tem veste, mas não tem corpo, está oco.

Novamente, trazendo para nosso contexto específico, quanto à relação sujeito e objeto de arte, a dialética da ausência do corpo presente, também poderia servir de mote para pensar em um sujeito sem corpo, analogamente em "cérebros em barris de vidro". Poderíamos evocar também um sujeito que não se permite capturar, pois habita fora de si, alienado. E, se esse sujeito não se permite capturar, como definir sua

8 Sobre este tema, o universo como um sistema, recomendo a leitura dos livros: GREEENE, B. Universo Elegante. Trad. José V. Filho. São Paulo, Companhia das Letras, 2001; LUFT, E. Sobre a Coerência do mundo. Rio de Janeiro: Civilização Brasileira, 2005. 
identidade?

Por outro lado, há restrições, como posto anteriormente, ao querer atribuir uma natureza que seja contrária a da materialidade do objeto, atribuindo-lhe predicações que contrariem a determinação do próprio objeto artístico, estaríamos a desconectar as relações pertinentes, omitindo suas imbricações factuais por meio de um agir arbitrário. Logo, o objeto de arte diz em parte o que ele é sem sua materialidade objetiva, porém, as demais camadas de significação, configuradas como devir, como processo, como dinâmicas, são construídas em um contínuo, mediante múltiplos antagonismos e protagonismos.

O reflexo da realidade, que aparece nas obras, não é um empréstimo de elementos ou unidades materiais, mas uma espécie de reestruturação; onde os antagonismos não resolvidos da realidade retornam aos objetos estéticos, como problemas imanentes de sua forma, como historiografias conscientes ou inconscientes de sua época, ou mesmo como topologias e topografias de estados informacionais que aparecem por meio de planos de significação.

Finalizando a argumentação, o objeto de arte pode "apoderar-se" dos agentes de fruição através de um apelo à razão que requeira um despertar consciente, quanto à compreensão de movimentos que estão presentes em sua estrutura intrínseca de estruturação. Logo, seria possível deduzir que as normas que fixam as relações entre agente produtor, fruidor e objeto de arte são tratadas como temporárias, provisórias; de maneira que o fruidor pode-se lançar, transpondo a mera observação, permitindo-se, inclusive, ser levado a pensar e formular um juízo, que envolve a escolha de valor (esfera ética), quanto ao que percebe (esfera estética), desembocando, assim, em participação reflexiva e autônoma na construção ampliada, no plano do tecido representacional da realidade.

Em síntese, a arte é autônoma em sua relação com o mundo, recorre a ele como fonte de seu material, e é necessária (em sentido deôntico), enquanto possui em si a capacidade de instigar a percepção de um outro estado de coisas, de perceber a natureza conciliatória (e não somente na aparente contradição) entre particular e universal. Mas que, num primeiro momento, aparece como impossibilidade racional, como aporia. Estas aparentes contradições estão expressas abundantemente em diversos contextos na contemporaneidade.

O caráter de necessidade da arte é autorreflexivo, como se fosse um espelho a mostrar múltiplas realidades, por meio de uma representação cifrada. Decifrar cabe ao fruidor, seu espaço é determinante nesta relação, pois para que se criarão objetos estéticos se não para estarem sujeitos à exposição, ao fruidor? A arte tem algo a dizer e não o diz explicitamente, nem de modo trivialmente conceitual, mediante conceitos estandardizados. Porém, não critica a linguagem conceitual que é incapaz de mostrar a verdade como totalidade. Ainda que se pretenda, nenhuma área de sistematização do conhecimento poderia fazê-lo, e o objeto de arte denuncia esta impossibilidade almejada como possibilidade em um devir. Este enigma é o amálgama entre necessidade e autonomia enquanto interdependentes, que intentamos desenvolver introdutoriamente.

A arte que toma o choque como princípio fundamental é a que serve de refúgio em sua própria negação. Em seu direito à existência, ela precisa transcender seu 
próprio conceito para não ser capturada e forçada a encerrar-se como sendo isso ou aquilo, de modo que seja negado seu crescimento. Sua conceituação deve permanecer aberta ao devir, por isso não é possível defini-la. De modo hiperbólico, e em última análise, o andar humano é desejoso de conhecer o incognoscível, expressar o inexprimível e dizer o inefável, pois para preencher seu conceito precisa superar-se continuamente.

\section{REFERÊNCIAS}

ABAGNANO, N. Dicionário de Filosofia. Trad. Alfredo Bossi. 5 ed. São Paulo: Martins Fontes, 2007.

ADORNO, T. Negative dialectics. New York: The Continuum Publishing Company, 1999.

BAUDRILLARD, J. O sistema dos objetos. Trad. Zulmira R. Tavares. São Paulo: Ed. Perspectiva, 1973.

BODEN, M. A. Dimensões da criatividade. Trad. Pedro Theobald. Porto Alegre: Ed. Artes Médicas, 1999.

BODEN, M. A. Life and cognitio. In: Branquinho, J. In: The foundations of cognitive science. Oxford: Claredon Press, 2001.

BOHM, D. Totalidade e Ordem Implicada. Trad. Teodoro Lorent. São Paulo: Madras, 2008.

CALCATERRA, R. M. Ideias concretas: percurso na filosofia de John Dewey. Trad. Silvana C. Leite. São Paulo: Edições Loyola, 2015.

GOSWAMI, A. Criatividade Quântica: Como pensar nosso potencial criativo. Trad. Cássia Nasser e Marcello Borges. São Paulo: Aleph, 2008.

HANSON, R. N. Patterns of Discovery. Cambridge: Cambridge University Press, 1972. OLIVEIRA, N. R. de.; ZUIN, A.A.S.; PUCCI, B. Teoria Crítica, estética e educação. Campinas: Editora Autores Associados, 2001

PEIRCE, C. S. Collected Papers of Charles Sanders Peirce. Ed. Hartshorne, Weiss \& Burks. Cambridge: Harvard Univ. Press, 1935, 1958.

PEIRCE, C. S. Semiótica. Trad. José Teixeira Coelho Neto. São Paulo: Perspectiva, 1995 PEIRCE, C. S. Um argumento negligenciado para a realidade de Deus. Trad. Cassiano Terra. In: Revista Cognitio, v.4, n. 1, 2003.

SANTAELLA, L. Matrizes da linguagem e pensamento: sonora, visual, verbal - Aplicações na hipermídia. 3 ed. São Paulo: Iluminuras: FAPESP, 2005.

SILVEIRA, L.F.B. Curso de semiótica geral. São Paulo: Quartier Latin, 2007. 